\title{
A compact 5-nH one-phase-leg SiC power module for a 600V-60A-40W/cc inverter
}

\author{
Kohei Matsui ${ }^{1,2, a}$, Yusuke Zushi ${ }^{1,3}$, Yoshinori Murakami ${ }^{1,3}$, Satoshi Tanimoto ${ }^{1,3}$ \\ and Shinji Sato ${ }^{1,4}$
}

\author{
${ }^{1}$ R\&D Partnership for Future Power Electronics Technology (FUPET), Japan \\ ${ }^{2}$ Fuji Electric Co., Ltd., Fuji-machi, Hino, Tokyo 191-8502, Japan \\ ${ }^{3}$ Nissan Motor Co., Ltd., 1, Natsushima-cho, Yokosuka 237-8523, Japan \\ ${ }^{4}$ Sanken Electric Co., Ltd., 3-6-3, Kitano, Niiza, Saitama 352-8666, Japan \\ amatsui-kohei@aist.go.jp
}

Keywords: power module, low inductance, all-SiC inverter

\begin{abstract}
We have developed a small-volume, high-power-output inverter with a high output power density using $\mathrm{SiC}$ power devices. To fully utilize the advantages of $\mathrm{SiC}$ power devices, it is necessary to reduce the inductance of the power module. This is done by using a double-layer ceramic substrate, attaining a low inductance of $5 \mathrm{nH}$. A double pulse test was carried out up to 60 A under a DC voltage of $600 \mathrm{~V}$. The low inductance greatly reduced the surge voltage and the oscillation at the switching transient. The SiC inverter unit with a volume of $250 \mathrm{cc}$ was assembled using three power modules. The cooling performance of the inverter unit was evaluated at a loss equivalent to an output power of $10 \mathrm{~kW}$, and it was found that the inverter unit can output $10 \mathrm{~kW}$ at a junction temperature (Tj) of about $200^{\circ} \mathrm{C}$.
\end{abstract}

\section{Introduction}

We have been developing a $600 \mathrm{~V}-60 \mathrm{~A} 3$-phase inverter with a high output power density of $40 \mathrm{~W} / \mathrm{cc}$ using SiC power devices [1]. This requires a high $\mathrm{Tj}$ drive capability and low power device switching losses [2-4]. Low parasitic inductance is needed to attain low-loss switching because parasitic inductance causes various problems such as surge voltage and oscillations [4]. A one-phase-leg power module with low parasitic inductance has been developed to avoid such problems. This module has a compact size of $20 \mathrm{cc}$, including an air-cooled heatsink, and can operate at $\mathrm{Tj}$ higher than $200^{\circ} \mathrm{C}$. This paper describes: (1) the reduction of parasitic inductance in the module and (2) the cooling performance.

\section{All-SiC power module with double-layer ceramic substrate}

Figure 1 shows a photograph of a one-phase-leg SiC power module, and Fig. 2a shows the circuit configuration. Two SiC-JFETs (SXEC120R025, normally-off) and two SiC-SBDs (SDC30S120) (SemiSouth Laboratories, Inc.) are used for each arm. Capacitors were installed between gates and sources to prevent false turn-on of the JFETs [5]. A double-layer ceramic (Figs. 2b and 2c, Kyocera Co., Ltd.) is used for the substrate, consisting of three metal sheets $(\mathrm{Cu})$ and two ceramic sheets $(\mathrm{SiN})$. Parasitic inductance between terminals D1 and S2 during the switching transient is closely related to the area of the main current loop in the module. As shown in Fig. 2(b), the source of the low-side JFETs is connected to the top Cu sheet S2' by A1 wires. S2' is connected to the mid-layer $\mathrm{Cu}$ sheet via through holes, and the sheet is connected to S2 via another through hole. Therefore, the main current loop has a much smaller area than a conventional single-layer structure. At the switching transient, the main current flows as indicated by the arrows in Fig. 2c. This small current loop greatly reduces parasitic inductance through terminal D1 to S2; the inductance was 
estimated to be $4.5 \mathrm{nH}$ by 3D electromagnetic simulation. The drawback about using a double-layer ceramic substrate is a potential increase in heat resistance, but the effect is negligible in a high $\mathrm{Tj}$ drive system with forced air cooling because the heat resistance of the heatsink accounts for most of the overall heat resistance and the contribution of the substrate resistance is very small. The ceramic substrate is directly joined to the $\mathrm{Cu}$ heatsink in order to reduce the size. To achieve high $\mathrm{Tj}$ operation exceeding $200^{\circ} \mathrm{C}$, the materials were carefully selected.

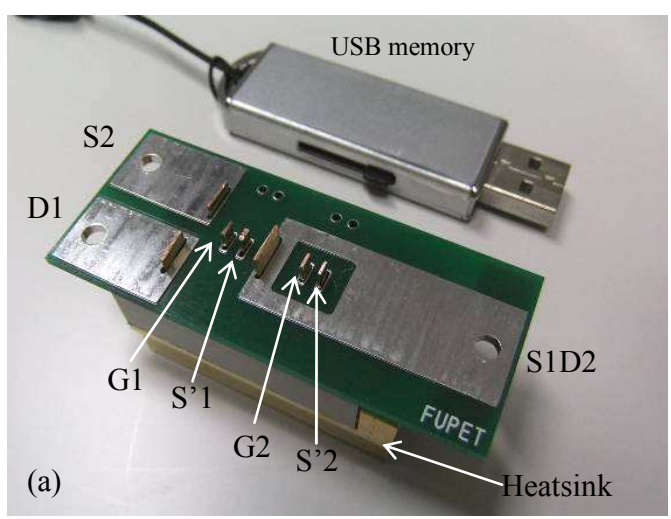

Fig. 1 Photographs of the power module: (a) outside view and (b) inside view.

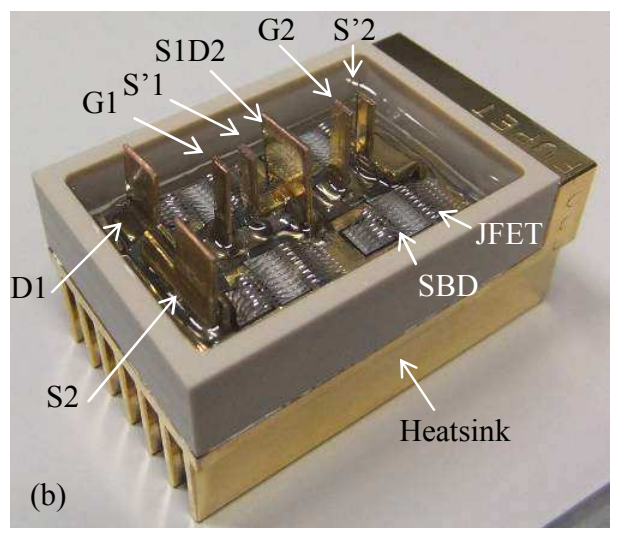

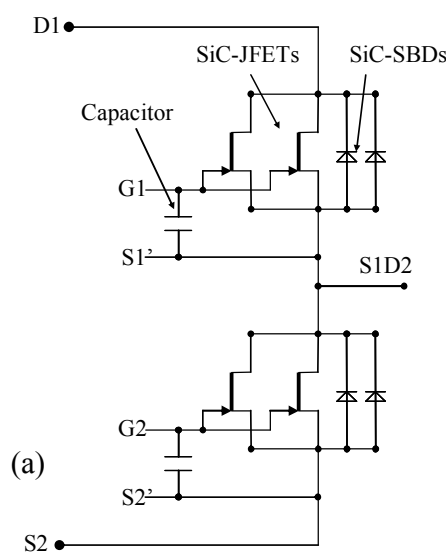

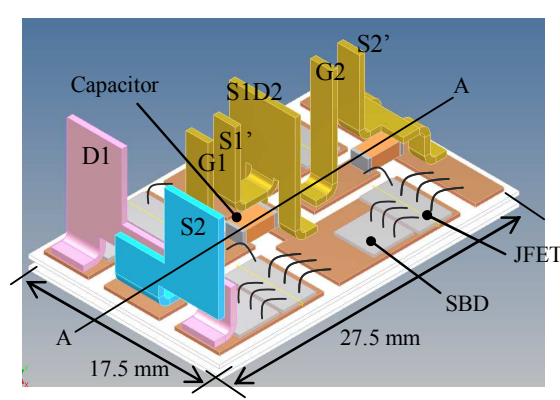

(b)

Fig. 2 Internal structure of the module:

(a) circuit configuration, (b) $3 \mathrm{D}$ view and (c) section A-A.

\section{Electrical evaluation}

A double pulse test was carried out under a DC voltage of $600 \mathrm{~V}$ [5]. A snubber capacitor (Murata, $300 \mathrm{nF}, 1 \mathrm{kV}$ ) was mounted between terminals D1 and S2. Figure 3 shows the turn-off, turn-on transient (JFET) and reverse recovery waveform (SBD) at a drain current of $60 \mathrm{~A}$. The black lines of $\mathrm{V}_{\mathrm{DS}}$ in Fig. 3 are the voltage waveforms obtained with a current transformer (CT) probe and the red lines are the waveforms without the CT probe. The red lines clearly show very low surge and very small oscillation, indicating that the module has a fairly small inductance. We attempted to evaluate the parasitic inductance through terminal D1 to S2 based on the current and voltage waveforms. However, a CT probe must be used to measure the current, and the wiring must be extended to connect a CT probe. This increased the inductance and caused spurious oscillation, as indicated by the $V_{\text {DS }}$ black lines. Another evaluation method was therefore used in which inductance was determined only from the voltage waveform (red line), and was calculated by:

$$
\int \Delta \mathrm{Vdt}=\mathrm{LI}_{\mathrm{D}},
$$



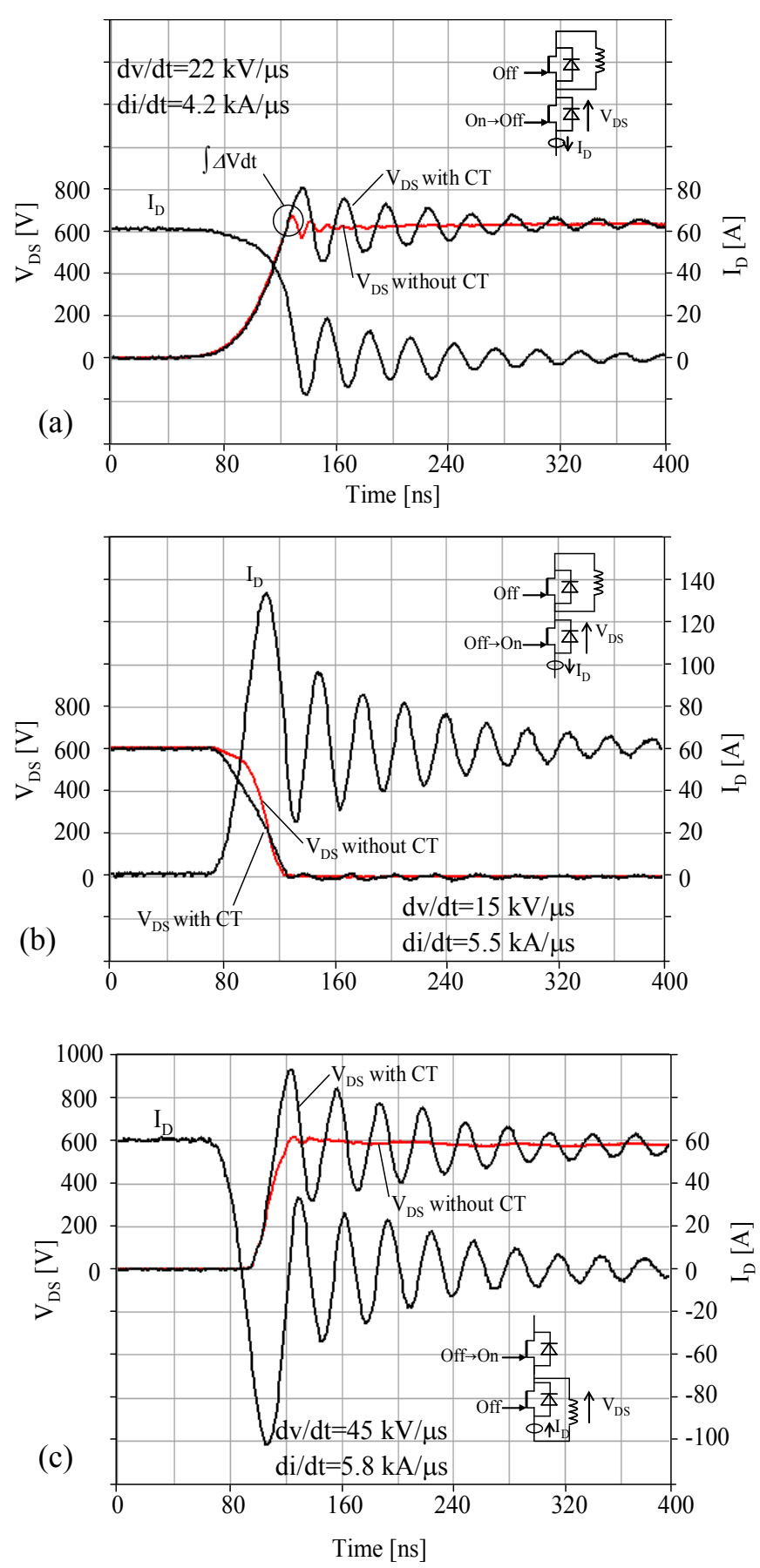

Fig. 3 Results of double pulse test at $I_{D}=60 \mathrm{~A}$ under a DC voltage of $600 \mathrm{~V}$ : (a) turn-off transient waveform (JFET), (b) turn-on transient waveform (JFET) and (c) reverse recovery transient waveform (SBD).

Table 1 Inductance measurements

\begin{tabular}{|c|c|c|}
\hline Method & Components & $\mathrm{L}$ \\
\hline $\begin{array}{c}\text { Electromagnetic } \\
\text { simulation }\end{array}$ & Module & $4.5[\mathrm{nH}]$ \\
\hline Impedance analyzer & Module & $5.5[\mathrm{nH}]$ \\
\cline { 2 - 3 } & Snubber capacitor & $3.7[\mathrm{nH}]$ \\
\hline Double pulse test & $\begin{array}{c}\text { Module }+ \\
\text { Snubber capacitor }\end{array}$ & $9.3[\mathrm{nH}]$ \\
\hline
\end{tabular}

where $\int \Delta \mathrm{Vdt}$ is obtained by integrating the area of the first surge voltage waveform over the line of $600 \mathrm{~V}$, as shown in the circled area in Fig. 3a, $\mathrm{L}$ is the synthetic inductance of the module and the snubber capacitor, and $\mathrm{I}_{\mathrm{D}}$ is the current flowing through the $\mathrm{SiC}$ chips. Figure 4 plots $\int \Delta \mathrm{Vdt}$ obtained by varying $\mathrm{I}_{\mathrm{D}}$ from 20 to $60 \mathrm{~A}$ where the slope in the $\int \Delta \mathrm{Vdt}-\mathrm{I}_{\mathrm{D}}$ relationship corresponds to the inductance $\mathrm{L}$. Thus, the inductance $\mathrm{L}$ is estimated to be $9.3 \mathrm{nH}$. The static inductances were also measured by using an impedance analyzer. However, since the inductance of the probe causes a significant error when $L$ is several $\mathrm{nH}$, accurate measurement is difficult. Therefore, the static inductance is for reference only. Table 1 shows the inductances obtained by simulation, double pulse test and impedance analyzer. Judging from each evaluation result, the module inductance is estimated to be about $5 \mathrm{nH}$.

\section{Thermal evaluation of the inverter}

The three-phase $\mathrm{SiC}$ inverter unit was assembled as shown in Fig. 5. This inverter unit was designed to attain an output power density of $40 \mathrm{~W} / \mathrm{cc}$, and its specifications were as shown in Table 2. The body of the inverter unit consists of three power modules with heatsink, cooling fan, DC linked capacitors and the case. The inverter unit is designed so that $\mathrm{Tj}$ is $200{ }^{\circ} \mathrm{C}$ when the output is $10 \mathrm{~kW}$ and ambient temperature is $25^{\circ} \mathrm{C}$. The fans are chosen to make the air flow between the fins of the heatsink $2 \mathrm{~m} / \mathrm{s}$. Measured and simulated temperatures of the heatsink versus heat loss from the unit are indicated by dotted and dashed lines in Fig. 6, respectively. The measured and simulated heat resistances are $0.91{ }^{\circ} \mathrm{C} / \mathrm{W}$ and $0.90^{\circ} \mathrm{C} / \mathrm{W}$, respectively, showing an error of less than $1 \%$. Using the same simulator, the heat resistance between the chip and heatsink can be calculated as $0.05^{\circ} \mathrm{C} / \mathrm{W}$. Therefore, $\mathrm{Tj}$ can be estimated as the solid line in the figure, which is approximately $10{ }^{\circ} \mathrm{C}$ higher than that of the heatsink. Based on these estimations, the heat loss will become approximately 180 $\mathrm{W}$ when the inverter unit output is $10 \mathrm{~kW}$, yielding an efficiency of $98.2 \%$. Therefore, the unit can output $10 \mathrm{~kW}$ power with $\mathrm{Tj}$ of $200{ }^{\circ} \mathrm{C}$. 


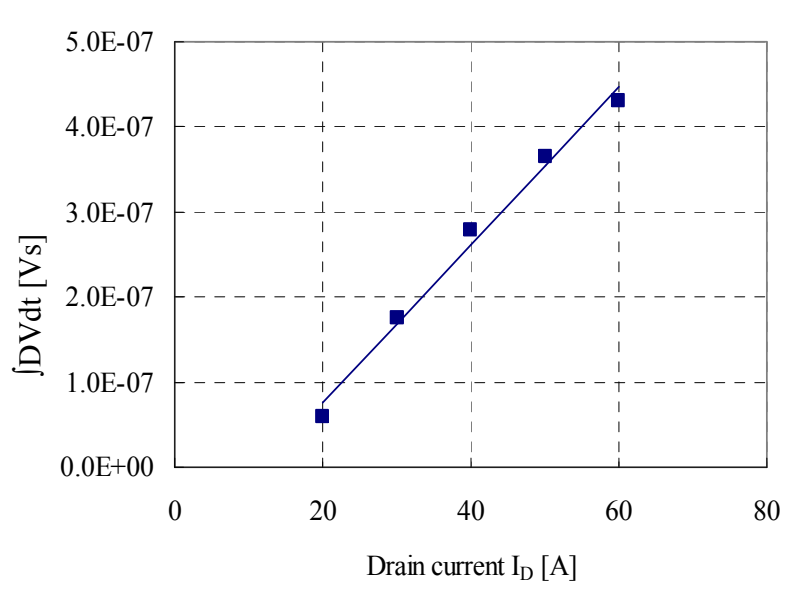

Fig. 4 Relationship of $\int \Delta \mathrm{Vdt}=\mathrm{LI}_{\mathrm{D}}$ from $\mathrm{I}_{\mathrm{D}}=20$ to $60 \mathrm{~A}$.

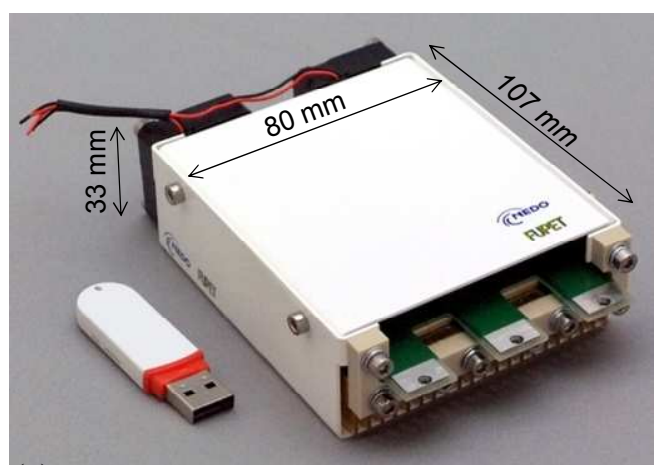

(a)

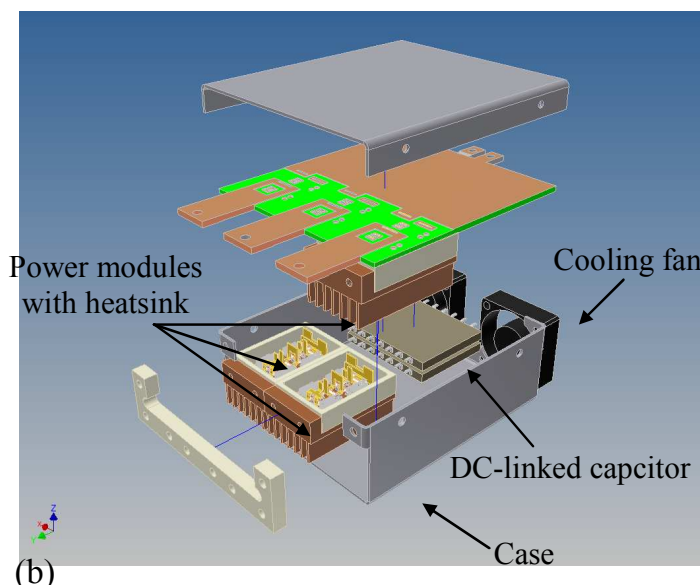

Fig. 5 Assembled inverter:

(a) photograph and (b) exploded view.

Table 2 Specifications of the inverter

\begin{tabular}{|l|l|}
\hline Input & DC600 V \\
\hline Output & $3 \phi-400 \mathrm{~V}, 10 \mathrm{~kW}$ \\
\hline Size & $107 \times 80 \times 33 \approx 250 \mathrm{cc}$ \\
\hline Power density & $40 \mathrm{~W} / \mathrm{cc}$ \\
\hline Switching frequency & Up to $50 \mathrm{kHz}$ \\
\hline
\end{tabular}

\section{Summary}

We achieved a power module with a low inductance of $5 \mathrm{nH}$ by using a double-layer ceramic substrate. The surge voltage and oscillation were markedly reduced at the switching transient. A three-phase inverter unit with a $10 \mathrm{~kW}$ rating and $250 \mathrm{cc}$ in volume was assembled. The results of thermal radiation tests suggested that our inverter unit can work at $\mathrm{Tj}$ of about $200{ }^{\circ} \mathrm{C}$, with an output power density of 40 $\mathrm{W} / \mathrm{cc}$.

\section{Acknowledgement}

This work was supported by a grant from the Green IT Project directed by the New Energy Industrial Technology Development Organization (NEDO) of Japan.

\section{References}

[1] S. Sato, K. Matsui, Y. Zushi, Y. Murakami, S. Tanimoto, H. Sato and H. Yamaguchi, Mater. Sci. Forum, Vols. 679-680 (2011), pp. 738-741.

[2] E. Cilio, J. Homberger, B. McPherson, R. Schupbach, A.B. Lostetter and J. Garrett, APEC2007, pp. 666-672.

[4] I. Omura, M. Tsukuda, W. Saito and T. Domon, PCC2007, pp. 575-580.

[3] J. Hornberger, B. McPherson, J. Bourne, R. Show, E. Cilio, W. Cilio, B. Reese, E. Heinrichs, T. McNutt, M. Schupbach and A.B. Lostetter, HiTeN 2001, pp. 159-166.

[5] Semisouth Laboratories, Inc., Technical notes AN-SS3 6A JFET Gate Driver Optimized for High Speed Hard Switching.

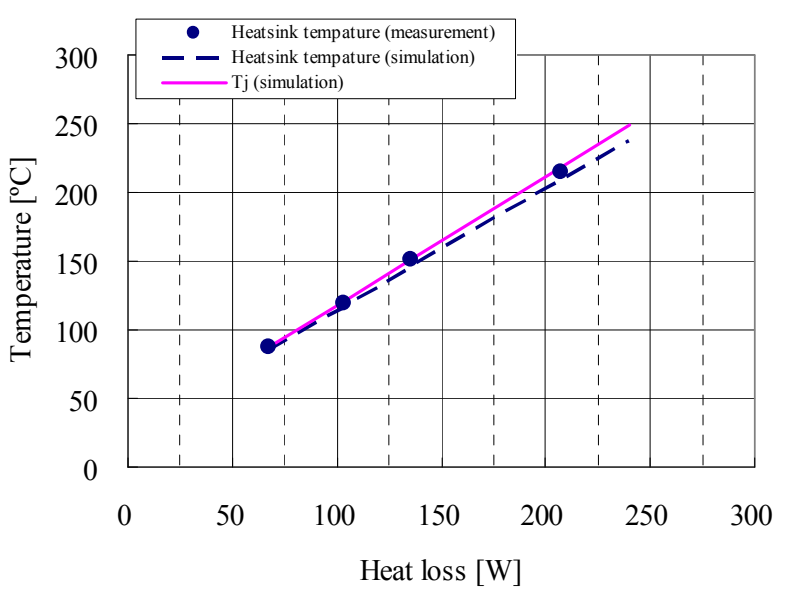

Fig. 6 Measured and simulated temperatures of heatsink versus heat loss 